\title{
Analysis of Optimized Dispatching of Micro-Grid
}

\author{
Jiahang Xia \\ North China Electric Power University, Beijing, 102206 \\ alanncepu@foxmail.com
}

Keywords: Micro-grid; Renewable energy; Optimal dispatching recently; Optimal economy

\begin{abstract}
Faced with the growing demand for electricity and the shortage of fossil fuels, the development of new sustainable renewable energy has become an urgent need. Some environment-friendly energy source, such as wind power and solar power, becomes increasingly mature.

Renewable energy is divided into large-scale centralized access and distributed access according to its access to the power system. Distributed access is mainly used in micro-grid, which refers to a small power distribution system consisting of distributed power supplies, energy storage devices, energy conversion devices, loads, monitoring and protection devices. How to properly manage the micro-grid internal distributed power and energy storage operation, to achieve micro-grid economy, technology, and environmental efficiency maximization has become an important research topic.

The economic scheduling problem recently refers to consider the grid side of the time-sharing price, then make full use of micro-grid batteries and other means of control to achieve the optimal economy operation under the forecast of the wind power output, photovoltaic output, and conventional load on a day (the next 24 hours).

Based on a micro-grid system consisting of fan, PV, battery and conventional load, this paper analyzes the optimal everyday scheduling of each part of micro-grid and propose a scientific and reasonable strategy to ensure the comprehensive benefit of multiple stakeholders.
\end{abstract}

\section{Model Establishment and Calculation}

Model Establishment. Dividing one day into 96 equal periods (15 minutes per time period), we can get the data of the change of machine loads, fans and PV. Supposing that the power of every part does not change much, then we can establish a model to analyze.

We can also get the purchase price and sale price price of micro-grid in each period by searching the data. The price is shown in table 1-1.

Table1. Sale price and purchase price

\begin{tabular}{ccccccc}
\hline Period & $0: 00-7: 00$ & $0: 00-7: 00$ & $0: 00-7: 00$ & $0: 00-7: 00$ & $0: 00-7: 00$ & $0: 00-7: 00$ \\
\hline $\begin{array}{c}\text { Sale price } \\
\text { (yuan/kwh) }\end{array}$ & 0.22 & 0.42 & 0.65 & 0.42 & 0.65 & 0.42 \\
$\begin{array}{c}\text { Purchase price } \\
\text { (yuan/kwh) }\end{array}$ & 0.25 & 0.53 & 0.82 & 0.53 & 0.82 & 0.53 \\
\hline
\end{tabular}

1. The composition of objective function

The total cost of the system includes the wind power generation $\operatorname{cost} \mathrm{C}_{\mathrm{w}}$, the solar power generation cost $C_{S}$, the battery discharge $\operatorname{cost} C_{b}$, the electricity purchase cost from the grid $C_{G 1}$, the electricity sale profit to grid $\mathrm{C}_{\mathrm{G} 2}$.

So the objective function of the load power supply cost is

$$
C=C_{W}+C_{s}+C_{G 1}-C_{G 2}+C_{b}
$$

Solar power generation cost is: 
$\mathrm{C}_{\mathrm{s}}=\mathrm{A}_{\mathrm{s}} \sum_{\mathrm{t}=1}^{\mathrm{T}} \mathrm{P}_{\mathrm{s} . \mathrm{t}} \Delta \mathrm{t}$

$A_{s}$ means solar power supply unit price, $A_{s}=0.75 y u a n / \mathrm{kWh}$.

Wind power generation cost: $\quad \mathrm{C}_{\mathrm{w}}=\mathrm{A}_{\mathrm{w}} \sum_{\mathrm{t}=1}^{\mathrm{T}} \mathrm{P}_{\mathrm{w} . \mathrm{t}} \Delta \mathrm{t}$

$\mathrm{A}_{\mathrm{w}}$ means wind power supply unit price, $\mathrm{A}_{\mathrm{w}}=0.52 \mathrm{yuan} / \mathrm{kWh}$.

Battery discharge cost: $C_{b}=A_{b} \sum_{t=1}^{T} P_{\text {dis.t }} Y_{t} \Delta t$

$A_{b}$ means battery discharge unit price. $A_{b}=0.2 y u a n / \mathrm{kWh}$

The cost of purchasing electricity from the main grid:

$$
\mathrm{C}_{\mathrm{G} 1}=\sum_{\mathrm{t}=1}^{\mathrm{T}} \mathrm{A}_{\mathrm{G} 1 . \mathrm{t}} \mathrm{P}_{\text {dis.t }} \mathrm{Y}_{\mathrm{t}} \Delta \mathrm{t}
$$

$\mathrm{A}_{\mathrm{G} 1}$ means purchase price, as shown in the table1.

The profit of selling electricity to the main grid:

$\mathrm{C}_{\mathrm{G} 2}=\sum_{\mathrm{t}=1}^{\mathrm{T}} \mathrm{A}_{\mathrm{G} 2 . \mathrm{t}} \mathrm{P}_{\mathrm{G} 2 . \mathrm{t}} \mathrm{F}_{\mathrm{t}} \Delta \mathrm{t}$

$\mathrm{A}_{\mathrm{G} 2}$ means sale price, as shown in the table1.

\section{Restrictions}

(1) The restriction battery charge and discharge

The restriction of charge and discharge depth

The maximum charge or discharge power per unit time of the battery is $20 \%$ of the capacity of the battery. As follows, $0 \leq \mathrm{P}_{\text {cha.t }} \leq 0.2 \mathrm{E}_{\mathrm{b}} \mathrm{X}_{\mathrm{t}}$

$$
0 \leq \mathrm{P}_{\text {dis.t }} \leq 0.2 \mathrm{E}_{\mathrm{b}} \mathrm{Y}_{\mathrm{t}}
$$

The restriction of cycle charge and discharge

The discharge capacity of the battery should be equal to the charge power in the entire dispatch cycle. As follows, $\quad \sum_{\mathrm{t}=1}^{\mathrm{T}} \mathrm{P}_{\text {cha.t }} \mathrm{X}_{\mathrm{t}}=\sum_{\mathrm{t}=1}^{\mathrm{T}} \mathrm{P}_{\text {dis.t }} \mathrm{Y}_{\mathrm{t}}$

The restriction of charge and discharge process unique

In the scheduling interval, charging and discharging process can not occur at the same time. The state of charging and discharging status are expressed as 0 and 1. Zero means charging or discharging does not occur, and one means charging or discharging occurs.

$$
\text { As follows, } \quad \mathrm{X}_{\mathrm{t}} \mathrm{Y}_{\mathrm{t}}=0, \forall \mathrm{t} \in[1, \mathrm{~T}]
$$

The restriction of charge and discharge times

The maximum number of times of charging (N1) or discharging (N2) is limited to 8 times within a day.

So, as follows

$$
\begin{gathered}
\sum_{\mathrm{t}=1}^{\mathrm{T}}\left|\mathrm{X}_{\mathrm{t}+1}-\mathrm{X}_{\mathrm{t}}\right| \leq \mathrm{N}_{1} \\
\sum_{\mathrm{t}=1}^{\mathrm{T}}\left|\mathrm{Y}_{\mathrm{t}+1}-\mathrm{Y}_{\mathrm{t}}\right| \leq \mathrm{N}_{2}
\end{gathered}
$$

The restriction of remaining power

In order to prevent overcharge and overdischarge of the the battery, the battery remaining capacity and total capacity ratio should meet the upper and lower limit constraints, as follows,

$$
\begin{aligned}
\mathrm{E}_{1}=0.4 \mathrm{E}_{\mathrm{b}}+\mathrm{P}_{\text {cha. } 1} \mathrm{X}_{1} \Delta \mathrm{t}-\mathrm{P}_{\text {dis. } 1} \mathrm{Y}_{1} \Delta \mathrm{t}, \mathrm{t}=1 \\
\mathrm{E}_{\mathrm{t}}=\mathrm{E}_{\mathrm{t}-1}+\mathrm{P}_{\text {cha. } \mathrm{t}} \mathrm{X}_{\mathrm{t}} \Delta \mathrm{t}-\mathrm{P}_{\text {dis.t }} \mathrm{Y}_{\mathrm{t}} \Delta \mathrm{t}, 2 \leq \mathrm{t} \leq \mathrm{T} \\
0.3 \mathrm{E}_{\mathrm{b}} \leq \mathrm{E}_{\mathrm{t}} \leq 0.95 \mathrm{E}_{\mathrm{b}}
\end{aligned}
$$

(2) The restriction of power balance

As the battery can only be charged by the outside. So at any time interval, battery charging power is equal to the outside of the battery to charge the power. So, we have

$$
\mathrm{P}_{\mathrm{s} . \mathrm{t}}+\mathrm{P}_{\mathrm{w} . \mathrm{t}}-\mathrm{P}_{\mathrm{l} . \mathrm{t}}+\mathrm{P}_{\mathrm{G} 1 . \mathrm{t}} \mathrm{I}_{\mathrm{t}}-\mathrm{P}_{\mathrm{G} 2 . \mathrm{t}} \mathrm{F}_{\mathrm{t}}=\mathrm{P}_{\text {cha.t }} \mathrm{X}_{\mathrm{t}}-\mathrm{P}_{\text {dis.t }} \mathrm{Y}_{\mathrm{t}}
$$

(3) The restriction of interaction with the main grid

The restriction of process uniqueness with main grid

It is clear that micro-grid cannot buy and sell electricity with main grid at the same time. Buying situation $I_{t}$ and selling situation $F_{t}$ are represented by variable 0 and 1 .Zero means there is buying or selling behaviour with main grid, one means the behaviour happens. So, we have 


$$
\mathrm{I}_{\mathrm{t}} \mathrm{F}_{\mathrm{t}}=0, \quad \forall \mathrm{t} \in[1, \mathrm{~T}]
$$

The restriction of exchange of power with main grid

According to the data, the given micro-grid and the main grid limit the switching power under $150 \mathrm{~kW}$, so,we have $\quad 0 \leq \mathrm{P}_{\mathrm{G} 1 . \mathrm{t}} \leq 150 \mathrm{I}_{\mathrm{t}}$

$$
0 \leq \mathrm{P}_{\mathrm{G} 2 . \mathrm{t}} \leq 150 \mathrm{~F}_{\mathrm{t}}
$$

(4) The restriction of renewable energy power generation

$$
\begin{aligned}
& 0 \leq \mathrm{P}_{\mathrm{w}} \leq \mathrm{P}_{\mathrm{w} \max } \\
& 0 \leq \mathrm{P}_{\mathrm{S}} \leq \mathrm{P}_{\mathrm{S}_{-} \max }
\end{aligned}
$$

Model Calculation Results. The lingo software was used to solve the optimal value of eight decision variables $\left(\mathrm{P}_{\mathrm{G} 1}, \mathrm{P}_{\mathrm{G} 2}, \mathrm{P}_{\mathrm{cha}}, \mathrm{P}_{\mathrm{dia}}, \mathrm{X}, \mathrm{Y}, \mathrm{I}, \mathrm{F}\right)$ in 96 intervals. We selected four most representative groups of data, which is shown in Table 2 .

Table 2. Part of the results

\begin{tabular}{ccccc}
\hline $\begin{array}{c}\text { Interval } \\
\text { number }\end{array}$ & $\begin{array}{c}\text { The main grid } \\
\text { output power } \\
(\mathrm{kW})\end{array}$ & $\begin{array}{c}\text { The wind } \\
\text { output power } \\
(\mathrm{kW})\end{array}$ & $\begin{array}{c}\text { The solar } \\
\text { output power } \\
(\mathrm{kW})\end{array}$ & $\begin{array}{c}\text { The battery } \\
\text { output power } \\
(\mathrm{kW})\end{array}$ \\
\hline 1 & -38.8 & 163.1 & 0 & -60 \\
2 & -75.97 & 201.47 & 0 & -60 \\
63 & 90.59 & 10.47 & 59.41 & -10.37 \\
64 & 99.24 & 16.35 & 50.76 & -16.35 \\
\hline
\end{tabular}

\section{Comprehensive Benefit Analysis of Micro-Grid}

The Interests of the Respective Demand in Micro-Grid. Micro-grid involves a number of stakeholders, mainly including the load, the main grid, renewable energy and the battery, their relationships are shown in the Fig.1.

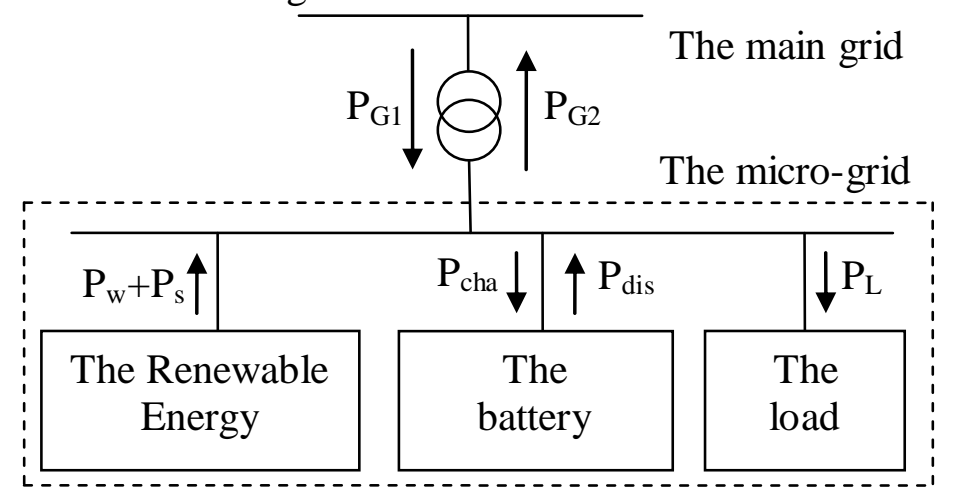

Figure1. The relationships between micro-grid with other parts

The load can only get power from the micro-grid bus and renewable energy can only supply power to the micro-network bus.But there are two-way power exchange channels between battery and micro-grid bus, micro-grid bus and main grid.

In order to balance the interests' conflict, we need to consider the optimization goals of them and find an optimal solution to the three optimal solutions as close as possible, thus transforming three single objective optimization problems into a multi - objective optimization problem.

These three kinds of interest demands are:

The demands of the user interests: the lowest price under the premise of meeting their electricity needs.

The demands of the grid interests: to cut the peak as much as possible and fill valley of the grid and reduce the load fluctuation and the magnitude of the fluctuation. 
The demands of the battery and renewable energy interests: To maximize the utilization of the wind and reduce the wind and solar abondonment rate.

Conflicts of Interest Among Micro-Grid. According to the analysis, abandoning wind and solar appropriately, reducing the utilization of renewable energy can reduce the cost of users. The input of the battery can increase the utilization rate of renewable energy and limit the instantaneous switching power between the micro-grid and the power grid at the same time, which is equivalent to reducing the adverse effect of the micro-grid load fluctuation.

Based on the results of the calculation, the grid output - time trend (Figure 2 above) and the purchase price - time trend (Figure 2 below) is shown in figure2. Even if the renewable energy utilization is reduced, the micro-grid will still increase the peak and valley amplitude of the total load of the grid.But it's speculated that further reducing the utilization of renewable energy can make it possible to reduce the exchange power between the micro-grid and the power grid and reduce the adverse effect. So I set a different range of renewable energy utilization (Represented by wind and solar abandonment rate) to observe the changes of power grid output under the different renewable energy utilization. The relationships between grid output and time diagram are shown in figure2.
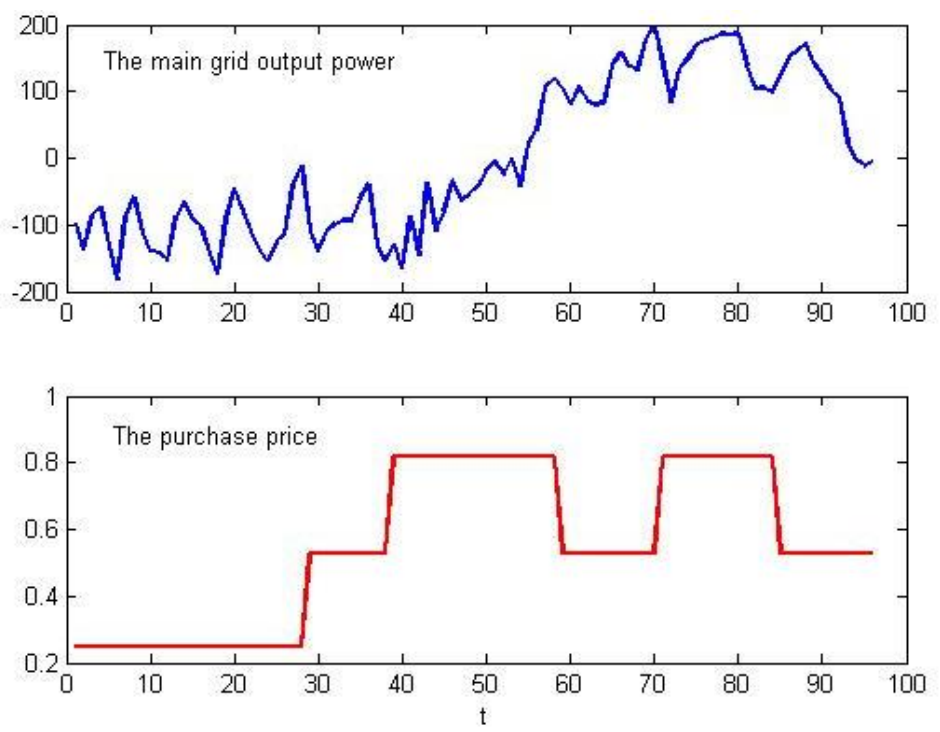

Figure2. The change of main grid output and purchase price

Strategy Formulation. Based on the calculation of the Lingo program, we get the trend of the main grid output with time under different wind abondonment rates, which is shown in figure 3 . It can be seen that setting a different abondonment rate of wind during a same period can really change the main grid output. Therefore, by setting the wind abondonment rate that minimizes the fluctuation of the grid, the fluctuation range of the grid load can be improved in each scheduling interval. To sum up, we propose the following improvements:

According to Figure 3, different wind abondonment rates can be set in different scheduling intervals to reduce the fluctuation range of the grid load.

Increasing the total capacity of the battery can limit the instantaneous switching power between the micro-grid and main grid to a greater degree.

In the provision of abandoned air rate, in order decrease the excessive waste, do not set a high wind rate. However, this will also affect the cost of load's electricity and increase the grid's magnitude of the fluctuation to a certain extent. 


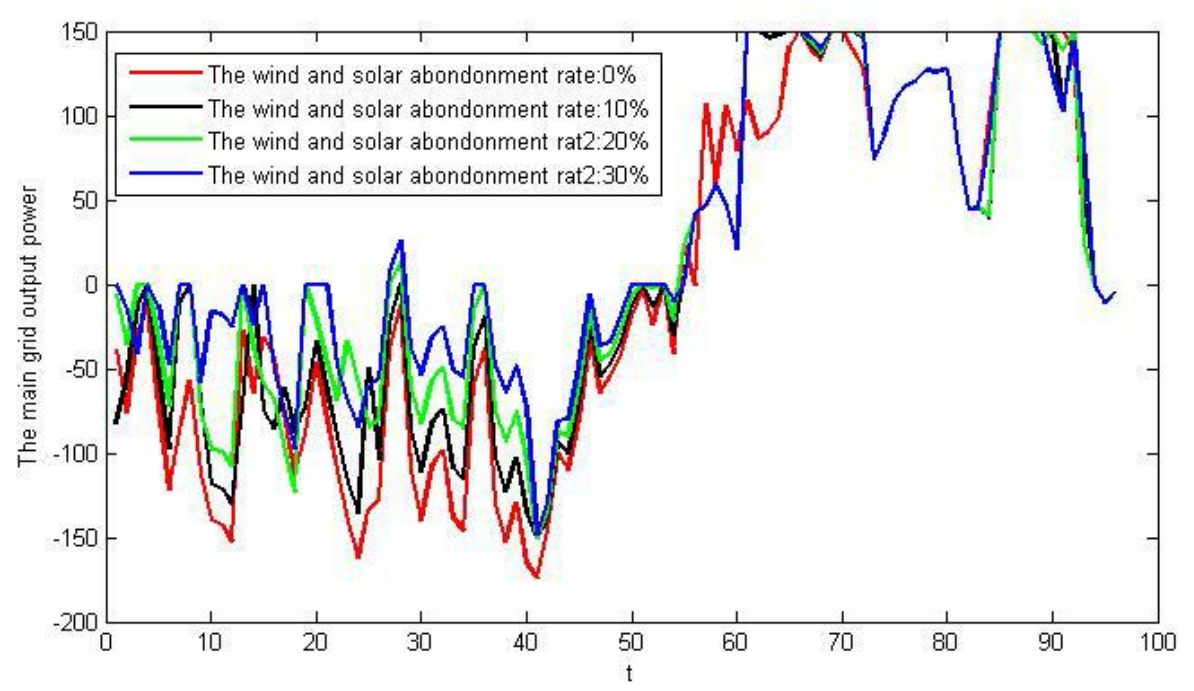

Figure3. The main grid output power after limiting the wind and solar abondonment rate

\section{Conclusion}

As the number and capacity of micro-grids continues to increase, upgrading the economy of microgrids is significant to the current situation of global energy shortage.

The new energy micro-grid discussed in this paper has the disadvantages of large fluctuation and uncertainty in the use of wind energy and solar energy. In order to ensure the stability of its power supply, it needs to be connected with the large power grid. Therefore, when optimizing it in economic perspective, not only the benefits of micro-grid, wind utilization and load electricity unit price should be considered, but also the influence of the connected grid to the stability of the grid operation should also be within consideration.

Too much emphasis on the utilization of renewable resources will lead to excessive load electricity costs and increase the instantaneous switching power among the micro-grid. In addition, too much consideration to reduce the cost of electricity costs will in turn cause serious waste of wind and solar resources and increase the burden of power supply. What's more,too much attention to reduce the power grid and micro-grid power exchange between the load will lead to increased costs. Three factors are mutually constrained, so it should be considered from the overall perspective and concessions should be made, so that the overall benefits can be maximized.

During further exploration, we also found that due to the fact that the relationships of the utilization of renewable energy and micro-grid power exchange power are changing with time, so we can intelligently optimize the operation of the micro-grid by regulate the utilization of wind and light using time-sharing approach.

\section{References}

[1] Shi kaituo. Random match micro-grid market model under the trading mechanism [D]. North China Electric Power University (Beijing), 2016.

[2] Xie Jinxing. Optimization modeling and LINDO / LINGO software [M]. Tsinghua University Press, 2005.

[3] Wu Xiong, Wang Xiuli, Cui Qiang. Micro-grid economic optimization operation considering demand-side management [J] Xi'an Jiaotong University, 2013, 47 (6): 90-96.

[4] MAO Xiao-ming, CHEN Shen, WU Jie-kang, etc.Optimal scheduling of battery-based microgrid under time-based tariff mechanism [J]. Power System Technology, 2015, 39 (5): 1192-1197.

[5] CHEN Jian, LIU Yu-tian, ZHANG Wen, etc.Optimization of multi-stage microgrids in 
distribution network based on game theory [J]. Automation of Electric Power Systems, 2016, 40 (1): 45-52.

[6] Li Yansong. Microinterconnect optimal scheduling of grid operation and real-time control method [D]. North China Electric Power University (Beijing), 2016.

[7] Huang Wei, Huang Ting, Zhou Huan, et al. Dynamic and Economical Optimal Scheduling of Microgrid Based on Improved Differential Evolution Algorithm [J]. Power System Automation, 2014, 38 (9): 211-217.

[8] Miao Yuyang. Micro-grid optimization scheduling [D]. North China Electric Power University, 2013.

[9] Cao Yu.Study on Optimal Dispatching of Isolated Microgrids for Hybrid New Energy [D]. Shanghai Institute of Electrical Engineering, 2016.

[10] Yang Yi, Lei Xia, Ye Tao, etc. Consider microgrid energy security and reliability of optimal scheduling [J] Chinese Society for Electrical Engineering, 2014, 34 (19): 3080-3088. 